\title{
DISCOVERING THE PRIMARY AND SECONDARY FACTORS THAT INFLUENCED THE FIRST PHILIPPINE ACADEMIC INSTITUTION TO ADOPT ENTERPRISE ARCHITECTURE
}

\author{
dela Cruz MEJV* and Ching MRD \\ College of Computer Studies, De La Salle University, 2401 Taft Ave, Malate, Manila, 1004 \\ Metro Manila, Philippines
}

\begin{abstract}
Academic Institutions utilize various ICT mechanisms to manage institution data, retrieve information, sustain financial activities, and deal with digital culture to create the learning and teaching setting. Thus, Enterprise Architecture (EA) is the ICT strategy employed in the domain to engage with radical changes and permuting trends. The purpose of EA is to organize and standardize Information Technology (IT) components to align with institution's goals. Qualitative analysis was conducted to discover the factors that instigated the first academic institution in the Philippines to adopt EA as an ICT tool for its long-term strategy. The approach was an exploratory research design to closely examine data through thematic analysis, focusing on inductive reasoning that emphasizes the data convened from the semi-structured interviews with an open-ended question. The result of the interviews was graded as primary and secondary factors which influenced the adoption process. Primary factors are the elements that drives the EA adoption such as the organizational structure and human traits, while secondary factors consist of the characteristics of the transformation, specifically the intended techniques, proposed transformation capabilities, transformation obstacles and institutional perspectives. The purpose of this enquiry is to disseminate the primary and secondary factors, discovered from the first academic institution in the Philippines, to various academic institutions and other sectors with similar settings, as a learning ground and bedrock of future possibilities for EA adoption. Thus, the challenge for subsequent EA adopters is to utilize and strengthen the primary and secondary factors to boost the success of transformation for competitive advantage. The future research should gravitate towards factors of EA nonadoption in academic institutions and other sectors as EA is still emerging slowly particularly in the Philippines.
\end{abstract}

Keywords: Academic Institution; Enterprise Architecture; Adoption Factors, Digitalization, Knowledge management, Transformation Capabilities, Transformation Obstacles

\section{Introduction}

Rapid evolution of technology and business practices support institution's growth and the potential to transform the Information Technology (IT) and seamlessly align with business objectives and strategies. Organizations as well as academic institutions are in search for innovative strategies that can boost the realization of goals, thus complemented by technology. Information and Communications Technology (ICT) serves as a support system towards efficiency and accuracy within the enterprise. Allega in 2018 stated that technology counts more when it's directly 
implemented to the execution of a business outcome. EA is the process of optimizing the fragmented manual and automated business operations into an integrated context that is receptive to change and responsive to the realization of the business strategy (Josey, 2011).

Digital business changes the nature of EA and Technology Innovation. Based on the Seven Best Practices for Using EA to Power Digital Business in 2014, 70\% of organizations are investing in EA, either starting, restarting or renewing its EA efforts; EA is increasingly a business and technology strategic planning discipline that focuses on (1) linking EA to business and IT strategy, (2) enabling collaboration across business and IT, and (3) creating EA roadmaps and migration plans; $40 \%$ of EA teams have business, IT and EA practitioners either starting or actively engaged together in the development of EA projects and programs; and 52\% of EA teams are either extremely involve or very involved in investment decisions. Moreover, Gartner's Future Predictions for EA in the Next Decade analyzes that by 2020 (1) 55\% of organizations will have a continuous and integrated business and IT strategy planning effort, (2) $75 \%$ of the heads of EA will be a key strategic business and technology advisor, (3) $80 \%$ of successful organizations will rely on EA to orchestrate digital business ecosystems and digital platforms, and (4) EA efforts that focus on enabling investment decisions with transparent governance will double its business value.

Literature about EA discuss advantages and benefits to institutions. Through the application of EA to projects, institutions take better view of the outcome for both client and the economy in accomplishing changes (Plessius et al, 2014). Ross et al. (2006), Seymour et al. (2010), Jusuf and Kurina (2017), and Gong and Janssen (2019) explored several benefits of EA in different institutions. According to the literature, EA enables business and IT alignment, delivers manageable environment, integrate old and new systems, reduce processes, deliver stakeholder satisfactions, create better decision making and improve risk identification, efficiency and effectiveness in processes, and improved business operations, processes, and performance. Countries and in parts of Northern America for over 20 years, is now developing momentum in academic institutions as an important management instrument in supporting institutions to meet its long-term strategic goals. Hence, a critical factor in the successful implementation of EA is the support and commitment at an institutional level through the senior management team sponsorship and involvement. Without this it is unlikely that such an enterprise-wide initiative, that requires the buy-in and involvement of management and staff across the institution, will succeed.

This research explores the question: What are the fundamental factors that influenced an academic institution to adopt Enterprise Architecture? Based on academic institution qualitative research, the findings contribute to literature by identifying the primary and secondary adoption factors of EA in the Philippine context, thus initiate opportunities for further extensive research in the field of EA adoption. As the objective of the paper revolves on the identification of the factors that motivated and influenced an academic institution in the Philippines to adopt EA, a qualitative method will be employed through semi-structured interviews to broaden the understanding regarding the adoption of EA. Interviews will then transcribed to construct codes to describe the contents particularly the fundamental factors of EA adoption.

Related works provides literatures of existing EA adoption factors in different sectors. Following the related works, research methodology and data collection process were discussed. Furthermore, primary, and secondary factors discovered were managed to develop a thematic map for Philippine 
academic institution EA adoption factors, and the classification of factors based on the Chocolate Model of Change (Dormant, 2011) were presented in the results and discussion parts of the paper. This paper concludes with a synopsis of the results on the factors of EA adoption in the Philippine Academic Institution context, recommendation for further research and implications of the research.

\section{Related Work}

Enterprise Architecture (EA) has emerged as a discipline that can help steer the ship of the enterprise through both quiet and turbulent waters, charting a course from its current location to a future location in a safe and streamlines way. It has become more prevalent in recent years but the precepts to go back almost to the beginning of what is often termed the information age (Sparx Systems \& Maguire, 2017). Business Systems Planning (BSP), however, was the bedrock of Enterprise Architecture in 1960s maneuvered by Professor Dewey Walker along with IBM team and John Zachman (Kotusev, 2016; The Open Group, 2015). It is about a top-down planning methodology that uses the notion of architecture as a formal description of the relationship between business and information technology (IT), or rather, the proposed design of corporate information systems based on an organizational strategy.

EA has emerged as a critical discipline to ensure an enterprise and the organizations that it comprises an understanding of the significant elements from which it is made, from strategic goals down to business and IT components that assist in achieving those goals. The discipline also allows enterprises to create architectures that will transition from where they need to be. EA provides the blueprint for transforming the enterprise from the current state to the desired target state to achieve strategic developments according to EA Book of Knowledge (EABOK). It guides the organization to construct IT project, standards, and policies to attain the desired business results through standardizing and structuring IT infrastructure to align with business goals and strategies, and to support the rapid growth of technology. On the note, EA promotes discipline into the organization by imposing guidelines and consolidating processes for more consistency and governance.

Table 1. EA Adoption Factors Grouped by Chocolate Model of Change Elements (Dormant, 2011)

\begin{tabular}{lll}
\hline Category & Factors of Adoption & SLR Sources \\
\hline \multirow{2}{*}{ Change } & Architectural Knowledge & Kumwenda, 2017; Ahmad et al., 2019; Ting, 2020; Lo, 2020 \\
& Relative Advantage & Ahmad et al., 2019 \\
& Business and IT Alignment & Ting, 2020 \\
Adopters and & Connection & Ahmad et al., 2019; Ting, 2020; Lo, 2020 \\
Change Agents & Interpersonal Skills & Seppänen, 2014; Kumwenda, 2017; Ting, 2020 \\
& Awareness & Seppänen, 2014; Lo, 2020 \\
& Top Management Support & Seppänen, 2014; Ahmad et al., 2019; Ting, 2020; Lo, 2020 \\
& Coaching & Kumwenda, 2017; Ting, 2020 \\
& Commitment & Ting, 2020; Lo, 2020 \\
Organization & Organization size & Ahmad et al., 2019 \\
& Governance & Seppänen, 2014; Ahmad et al., 2019; Ting, 2020 \\
\hline
\end{tabular}


Vision

Readiness
Seppänen, 2014; Kumwenda, 2017; Ting, 2020; Lo, 2020

Ahmad et al., 2019, Ting, 2020

Literature were about diverse organizations with relatively related factors of adoption, and that composes of the characteristics of the elements of the Chocolate Model of Change (Dormant, 2011) which are: Change, Adopters, Change Agents, and Organization (CACAO). Based on the scholars, as presented in Table 1, adoption of EA requires architectural knowledge (Kumwenda, 2017; Ahmad et al., 2019; Ting, 2020; Lo, 2020) to acquire the relative advantage because of the business and IT alignment. Traits of both adopters and change agents should encompass awareness to change and commitment to the execution of EA complemented with interpersonal skills (Seppänen, 2014; Kumwenda, 2017; Ahmad et al., 2019; Ting, 2020; Lo, 2020). Furthermore, top management support, connection and coaching from change agents can boost the competency and efficiency of the adopters. Whereas, organization size is a significant factor in adoption as EA requires workforce in the development of architecture to attain the vision with governance (Seppänen, 2014; Kumwenda, 2017; Ahmad et al., 2019; Ting, 2020; Lo, 2020). Thus, institutions should evaluate the readiness of the organization itself and its people before embracing EA (Ahmad et al., 2019, Ting, 2020).

There are a number of adoption factors focusing on EA in various organizations and in academic institutions. Thus, majority of literatures emphasized organizational, technology and human dimensions as the structural factors of EA adoption (Dang and Pekkola, 2019; Paireekreng et al., 2018; Seymour et al., 2010). The gap that is intended to address of this research is to identify the principal and ancillary factors of EA adoption, particularly from the first academic institution in the Philippines to adopt EA. It will be beneficial for institutions and organizations to be familiar with the leading factors to serve as their guide and starting point to future EA adaptors. In the Philippines, there were only a few organizations that were able to successfully adopt and implement EA based on literature, one is an academic institution while the other is a government department. Therefore, this paper can be a bedrock of other organizations and institutions in the adoption of EA, specifically the capabilities needed to achieve successful EA to deliver competitive advantage. For this reason, the research desires to discover the factors that influenced the adoption of an academic institution in the Philippine context. In addition, the research will evaluate similarities and differences between the identified factors from the literature and the factors that will be derived from this research. Accordingly, discovered EA adoption factors from the thematic analysis of the research can contribute to the body of knowledge.

\section{Research Method}

The research emphasizes the factors that instigated an academic institution in the Philippines to adopt Enterprise Architecture as an ICT long-term strategy. A qualitative method with an exploratory research design was employed to understand the discover the story behind EA as a strategy and the factors of adoption in an academic institution in the Philippines. A semi-structured face-to-face interview with an open-ended question, and a structured interview through email were the methods employed in gathering data. Participants were exclusively involved to the EA project and from the academic institution domain with a nominal to significant comprehension in EA. 6 participants agreed and were interviewed providing valuable data as pivotal factors in strengthening the significance of 
the research. This qualitative analysis presents data as evidence to assess the real scenario in the academic institution based on its participants (Yin, 2015). Furthermore, concluded factors from the interviews bridge the enquiry of this research, that is to identify the fundamental elements or factors of EA adoption.

Consent forms were distributed to the selected participants before conducting the interviews as this is one of the most significant ethical elements in conducting research. The purpose and value of the interview were indicated in the informed consent form and request for the permission to record the dialogue for data transcription and decomposition were included. This will protect the anonymity and confidentiality of the participants. Hence, no names or any personal details will be disclosed, and the actual recording will be kept until the creation of final output. On the other hand, interview questions were guided by but not restricted to the following:

- EA background in the institution

- Processes of the institution before EA adoption

- The needs and challenges of the institution to embrace EA

- The motivations of the institution to investigate EA and adopt it and

- The future directions or expected outcomes of the institution to EA

Possible factors, challenges, and benefits from the interviews were treated using the thematic analysis of Braun and Clarke (2006). Thematic analysis is a foundational method for qualitative analysis that is complex, diverse, and nuanced according to Holloway and Todres (2003). This type of analysis was used to determine probably factors that are not present from related literatures, particularly the adoption of EA in academic institution in the Philippine context. Thus, the process of Braun and Clarke's (2006) thematic analysis contains the following steps:

- familiarization with data gathered (interviews, surveys through recordings, paper-based and personal interviews);

- assigning codes to data for content describing;

- searching for patterns or themes within the codes across different sources of data;

- analyzing of themes; and

- defining and naming engaging themes.

In addition, thematic analysis allows researchers to address huge data sets more conveniently by classification of themes. On the other hand, according to Cohen et al (2007), understanding, explaining, and demystifying social reality through the perspective of various participants is important. However, subjective analysis of the researcher requires careful judgment and reflection on the development of interpretations.

The approach of the researcher is an inductive reasoning that is to focus on the data gathered from the semi-structured interviews and not include simulation and written version of the interviews were imported to a QDA-software which was ATLAS.ti, for a detailed analysis.

The research consisted of 4 face-to-face semi-structured interviews with open-ended question for about 23-57 minutes per person. Participants were the Project Owner, Project Executive, 3 Project Managers (with technical skills), and 2 structured interviews through email to participants with technical support background. The semi-structured interviews were transcribed word-for-word then analyze each interview with thematic analysis along with the research questions to define codes and 
themes. Discovered themes were finalized and used as the factors that influenced the first academic institution in the Philippines to adopt EA.

\section{Presentation of Results}

Table 2 presented diverse codes from different participants in alphabetical order. The codes driven were based on the word-for-word analysis from the interview transcriptions, with an average of 60 codes per person. A thematic map that was derived from the factors of adoption were also presented in Figure 1. The thematic map was composed of the primary and secondary factors of the EA adoption of an academic institution. The factors of EA adoption were the following:

- The primary factor is "Human and Traits" - Human and traits were the main drivers of EA adoption in the academic institution. It embodies all individuals who are connected to the transformation and the qualities or characteristics of change agents and adopters to support the adoption, while

- The secondary factor is "Strategic Transformation" - Strategic Transformation consist of components of the change itself or the EA transformation. It evolves in 4 crucial elements which are (1) Institutional Perspectives are the vision of the academic institution executives upon the adoption of EA (i.e. Seamless, Streamlined, Systematic); (2) Transformation Capabilities are the satisfactory transformation needed to sustain the and to attain the academic institution's long-term strategy (i.e. Governance, Holistic Transformation, Communication, Assessment, Alignment); (3) Transformation Obstacles are the challenges of EA adoption (i.e. Resistance to change, Cost, Shift in job description, Laborious, Time consuming); and (4) Intended Techniques. Intended Techniques are the proposed structure of EA (i.e., Framework, Methodology, Standards)

Table 2: Sample Codes from Various Participants

\begin{tabular}{|c|c|c|c|c|c|c|}
\hline $\begin{array}{l}\text { Interviewee } \\
\text { Code }\end{array}$ & $\mathrm{P} 1$ & $\mathrm{P} 2$ & P3 & $\mathrm{P} 4$ & P5 & P6 \\
\hline \multirow[t]{3}{*}{ Perspective } & Administration & Administration & & & & \\
\hline & Management & Management & Management & Management & & $\begin{array}{l}\text { Manageme } \\
\text { nt }\end{array}$ \\
\hline & & Technical & Technical & Technical & Technical & Technical \\
\hline \multirow[t]{5}{*}{ Codes } & $\begin{array}{l}\text { Addressing } \\
\text { Gaps }\end{array}$ & Alignment & $\begin{array}{l}\text { Addressing } \\
\text { Gaps }\end{array}$ & Analysis & Holistic & Analysis \\
\hline & Adopting & $\begin{array}{l}\text { By request } \\
\text { system } \\
\text { development }\end{array}$ & Adopting & Buy-ins & Integration & Evaluation \\
\hline & Analysis & $\begin{array}{l}\text { Central } \\
\text { document }\end{array}$ & Challenge & $\begin{array}{l}\text { By request } \\
\text { system } \\
\text { development }\end{array}$ & $\begin{array}{l}\text { Job } \\
\text { description }\end{array}$ & Assessment \\
\hline & Awareness & EA as guide & Change & Convenience & Knowledge & \\
\hline & Beliefs & EA work & Convenience & $\begin{array}{l}\text { Digital } \\
\text { Transformati } \\
\text { on }\end{array}$ & People & \\
\hline
\end{tabular}




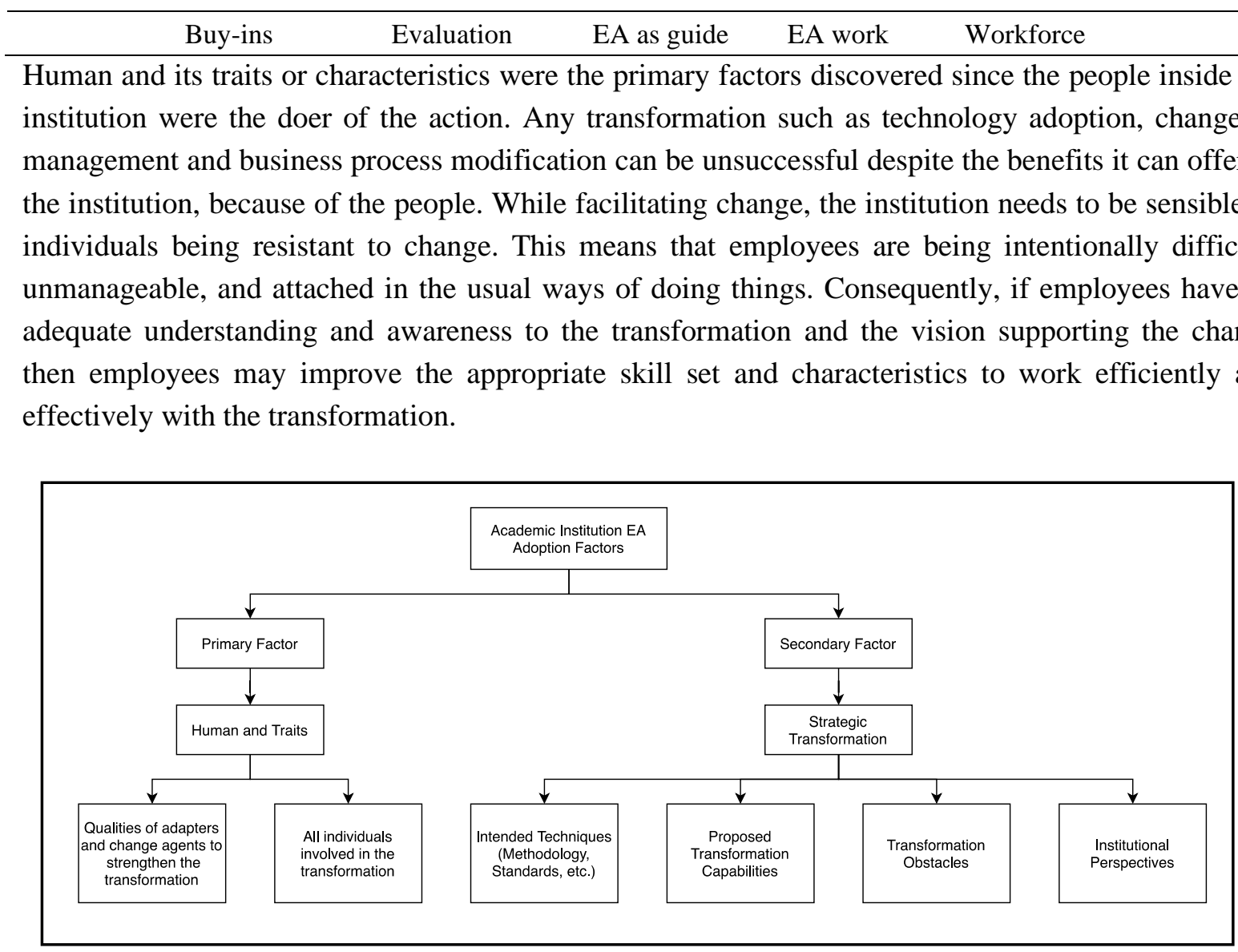

Figure 1: Thematic Map of Philippine Academic Institution Adoption Factors

Subsequent to human and traits, the factors to consider are the characteristic of the EA adoption, the challenges, and the vision towards the transformation. EA adoption focuses on the intended techniques and the transformation capabilities. On the other hand, the challenges highlight the obstacles in transforming and achieving its objectives, while the vision towards the transformation is about the perspectives of the top management in the institution. In adopting EA, assessment of the institution's vision is the initial step. Architects need to know the diverse stakeholder's perspective upon Enterprise Architecture adoption because the institutional perspectives or the vision will serve as the guide of the EA outcome. Thereafter, transformation capabilities or the strategic transformation needed by the academic institution should be determined. The transformation capabilities describe the "needs" and "wants" of the business, data, application, and technology (BDAT) architectures of the institution and can be derived through investigating the problems pertaining to BDAT perspectives. As a response to the antecedents of transformation capabilities, intended techniques should be proposed. Intended techniques will serve as the proposed parameters of the institution that will consist of the guiding framework, standards and policies, principles, and methodology to guide the institution's processes and most importantly, governing the institution's long-term strategy. 


\section{Discussion of Results}

The participants, from the Project Owner to the Project staffs, were evidently and consistently aware on the value of Enterprise Architecture in the Academic Institution's strategy. EA for them will lead to a holistic and integrated transformation that every department and offices within can progress.

"We wanted to make sure that we design systems, process and controls. So, when I saw that, I said, it's a good way to look at that the IT infrastructure address entire ecosystem rather than just one part. So, we started discovering what it's all about, discussing about it; and then once we got the whole of it, we proposed it in the steering committee so that's the reason why we started that project of ERP.” (P1 on Research Question \#2)

"Enterprise architecture for me is looking at the entire ecosystem and the connections and integrations between each part of the ecosystem. What are components that were defined that are in that ecosystem. What is the relationship of those to each other, how they flow? So, we're looking at business, the applications that run, the technology that supports it and the people. So, it's looking at everything." (P3 on Research Question \#1)

The intention is to align all the processes to have a sustainable, streamlined, and systematic institution that engages all the domains, not only IT side but the BDAT architectures through EA work and governance.

"For ITS, we would want to have a...to start off our level of maturity. We may just be an ad hoc right now on doing or having an EA capability for the university. In that, we can continue the business process architecture; we can maintain data architecture and govern data architecture. We choose, develop, or customize, or purchase that fits the architecture. And we have the appropriate technology to address outputs." (P2 on Research Question \#10)

"Passion will be visible to them. We can see his flowing passion for making this academic institution, world class. For making it relevant in the next 10 to 20 years. So, integrity and passion are a big factor for a person carrying the vision." (P3 on Research Question \#2)

The secondary factor focuses on transformation capabilities, siloed operational functions, fragmented systems, and diminishing of data duplication upon the adoption of EA, which was validated from the interviews. EA integrates all the islands of system, data, and processes seamlessly. The institution will not anymore be distressed on the real time updating of processes and documents; thus, operational tasks will be convenient because of the standards and policies, framework, and principles in place.

"To ensure maintenance of systems, without being too reliant on in-house IT staff (instead relying on vendor support and user support); to ensure real time update of data in all systems; to ensure real time update of documentation related to systems." (P5 on Research Question \#7)

"Conduct Systems Investigation with the user to fully determine their requirements. Do feasibility study based on the information gathered." (P6 on Research Question \#6 this is about the new process of requests)

"That time, we have islands of data because databases aren't linked yet. Much more when we were still fax-based, every application has its own database. If one office requested for the same system as the other, developers will just reuse the structure but will just add additional fields depending on the needs, since systems before were still 
not integrated. So that is the problem before, islands of system and with copies of their own databases." (P4 on Research Question \#6)

Change agents and adopters are very important during transformation for the realization of the vision. The adopters of change should acknowledge and fathom the pieces of detail of the transformation for EA to have a favorable outcome while change agents should guide and support the adopters by coaching and giving trainings concerning the change.

"The community will resist change too because change is something you also need to manage. People are very important in carrying that for moving forward because we would like, or I would like to believe, that with the adoption of EA, five or ten years down the road, we are not anymore part of the team, ERP is finished and we are now in different roads, the people will take over and continue with we are hoping that that is something that we can turn over." (P1 on Research Question \#9)

"First important human factor is being a good communicator. They know their audience. They know what to say. They know how to say it. They know the timing to say it. Sympathy. You have to understand where the audience are coming from, if they have fear that people will be replace, you have to sympathize and let them know and feel that they will not be replaced, that we'll take care of you. It is also very important that you are decisive. You know what decision to make, and you will be accountable of the decisions. So, it is important, I think for an architect to have those traits." (P3 on Research Question \#7)

Table 3: EA Adoption Factors grouped by the Chocolate Model of Change Elements

\begin{tabular}{|c|c|c|}
\hline Category & Factors of Adoption from Literatures & $\begin{array}{l}\text { Primary and Secondary } \\
\text { Factors of the Academic } \\
\text { Institution in the Philippines }\end{array}$ \\
\hline \multirow[t]{2}{*}{ Change } & Sufficient ICT Knowledge & \multirow[b]{2}{*}{$\begin{array}{l}\text { Strategic Transformation } \\
\text { (Intended Techniques and } \\
\text { Transformation Capabilities) }\end{array}$} \\
\hline & $\begin{array}{l}\text { Stakeholder Participation } \\
\text { Relative Advantage } \\
\text { Business and IT Alignment } \\
\text { Process Standardization }\end{array}$ & \\
\hline \multirow{9}{*}{$\begin{array}{l}\text { Adopters and } \\
\text { Change Agents }\end{array}$} & Communication & \multirow{9}{*}{$\begin{array}{l}\text { Human and Traits (Qualities } \\
\text { of Adopters and Change } \\
\text { Agents) }\end{array}$} \\
\hline & Skills & \\
\hline & Awareness & \\
\hline & Knowledge & \\
\hline & Involvement & \\
\hline & Support & \\
\hline & Participation & \\
\hline & Trainings & \\
\hline & Responsibility & \\
\hline \multirow[t]{5}{*}{ Organization } & Organization size & \multirow{5}{*}{$\begin{array}{l}\text { Strategic Transformation } \\
\text { (Institution Perspectives and } \\
\text { Transformation Obstacles) }\end{array}$} \\
\hline & Perceived Risks & \\
\hline & Governance & \\
\hline & Strategy/Vision & \\
\hline & Readiness & \\
\hline
\end{tabular}


Table 3 presents the relationship between the adoption factors from various literature and the primary and secondary factors of the Academic Institution in the Philippines that was classified into the Chocolate Model of Change Dimensions. Furthermore, the primary and secondary factors discovered in this research can significantly support the adoption in the academic institution because it was aligned and validated with the EA adoption factors from diverse literature. The research determined the primary and secondary adoption factors for an academic institution that can contribute as an additional factors of EA adoption in organizations aside from academic institutions.

\section{Conclusion}

The research aimed at discovering the primary and secondary adoption factors of EA in an academic institution and in the Philippine context through the Thematic Map of Philippine Academic Institution Adoption Factors. The domain of this paper focuses and delimits on the fundamental factors of first academic institution in the Philippines to adopt EA with the guidance of the Chocolate Model of Change (Dormant, 2011) through thematic analysis. Based on the transcribed interviews and from the results of the thematic analysis, the primary and secondary factors of EA adoption are the Human and Traits, and Strategic Transformation, consecutively. The Human and its Traits was identified as the primary factor of EA adoption since the adopters and change agents, complemented by their outstanding characteristics, are the founding drivers of transformation. Whereas the secondary factor of EA adoption focuses on the strategic transformation aspect which consist of the institutional perspectives, transformation capabilities, transformation obstacles and intended techniques.

Furthermore, the primary and secondary EA factors can broaden the realization of adoption in academic institution and in other sectors. The results of the research contribute to the body of knowledge of Enterprise Architecture and to the future adopters in the Academic Institutions in the Philippine context since there were just a few enquiries about EA in the Philippines. The study uncovered the primary and secondary factors, grouped into three significant domains (CACAO), that can serve as a guide to future adopters in different sectors. By exploring the value of the factors, aligned to the institution's needs, it can be a learning ground and bedrock of adoption. Institutions should investigate on ways to strengthen and develop the factor for value realization. Future research on the factors of EA non-adoption in academic institution and other sectors can be a promising study since majority of literatures about EA explored the factors of adoption of different macroorganizations.

CRediT Author Statement (Brand et al., 2015)

Ma. Eliza Jijeth V. dela Cruz: Conceptualization, Methodology, Investigation, Resources, Writing Original Draft, Writing - Review \& Editing. Dr. Michelle Renee D. Ching: Validation, Writing Review \& Editing, Supervision.

\section{References}

Ahmad, N. A., Drus, S. M., \& Bakar, N. A. A. (2019). Enterprise architecture adoption issues and challenges: A systematic literature review. Indonesian Journal of Electrical Engineering and Computer Science. https://doi.org/10.11591/ijeecs.v15.i1.pp399-408

Allega, P. (2018, February 02). Future Predictions for EA in the Next Decade. [Blog post]. Retrieved from https://blogs.gartner.com/philip-allega/2018/02/02/future-predictions-for-ea-in-the-next-decade/ 
Borra, A. \& Iluzada, E. (2016). Practical Enterprise Architecture as an ICT Strategy for De La Salle Philippines. DLSU 2016 Research Congress.

Braun, V. \& Clarke, V. (2006). Using thematic analysis in psychology. Qualitative Research in Psychology. https://doi.org/10.1191/1478088706qp063oa

Cohen, L., Manion, L. \& Morrison, K. (2007). Research methods in education $6^{\text {th }}$ edition. London: Routledge.

Dang, D. \& Pekkola, S. (2019). Institutional Perspectives on the Process of Enterprise Architecture Adoption. Information Systems Frontiers. https://doi.org/10.1007/s10796-019-09944-8

Dormant, D. \& Lee, J. (2011). The Chocolate Model of Change. San Bernardino, CA: publisher not identified

Gong, Y. \& Janssen, M. (2019). The value of and myths about enterprise architecture. International Journal of Information Management. https://doi.org/10.1016/j.ijinfomgt.2018.11.006

Holloway, I. \& Todres, L. (2003). The Status of Method: Flexibility, Consistency and Coherence.

International Organization of Standardization. (2011). ISO/IEC/IEEE 42010:2011 - Systems and software engineering -- Architecture description. ISOIECIEEE 420102011E Revision of ISOIEC 420102007 and IEEE Std 14712000. https://doi.org/10.1109/IEEESTD.2011.6129467

Josey, A. (2011). TOGAF Version 9.1 Enterprise Edition. The Open Group.

Jusuf, M. B. \& Kurnia, S. (2017). Understanding the Benefits and Success Factors of Enterprise Architecture. 10.24251/HICSS.2017.593.

Kotusev, S. (2016). The History of Enterprise Architecture: An Evidence-Based Review. Journal of Enterprise Architecture. 12. 29-37

Kumwenda, M. (2017). Enterprise Architect Roles and Competencies Within Medium to Large Scale Organizations [Master's thesis, University of Oslo]. http://urn.nb.no/URN:NBN:no-59590

Lo, S. K. (2020). Systematic Literature Reviews on Human Factors in Enterprise Architecture Implementation. https://doi.org/10.13140/RG.2.2.22775.78242

Maguire, S. (2017). Enterprise Architecture Enterprise Architect User Guide Series Author: Sparx Systems \& Created with https://sparxsystems.com.au/resources/user-guides/guidebooks/enterprisearchitecture.pdf

Paireekreng, W., \& Supasak, C. (2017). The Motivation of Implementation of Enterprise Architecture for Government Organization. Economics and Management Innovations (ICEMI). https://doi.org/10.26480/icemi.01.2017.307.308

Plessius, H. (2014). Perceived Benefits from Enterprise Architecture Complete Research. http://www.plessius.nl/pub/Perceived\%20benefits\%20from\%20EA.pdf

Ross, J. \& Weill, P. \& Robertson, D. (2006). Enterprise Architecture as Strategy - Creating a Foundation for Business Execution.

Seppänen, V. (2014). From Problems to Critical Success Factors of Enterprise Architecture Adoption.

Seymour, L, et al. (2010). Benefits and Factors Driving Enterprise Architecture Development in a Large South African Utility Company

Sparx Systems \& Maguire, S. (2019). Enterprise Architecture. Sparx Systems. Retrieved from https://sparxsystems.com/resources/user-guides/15.0/guidebooks/enterprise-architecture.pdf

The-Open-Group. (2015). TOGAF® Version 9.1 . In Open Group Standard.

Ting, Y. (2020). A Review of Models for Critical Success Factors Affecting Enterprise Architecture Implementation Yap Fei Ting. https://doi.org/10.13140/RG.2.2.18437.29921

Yin, R.K. (2014). Case Study Research and Applications Design and Methods. $6^{\text {th }}$ Ed. California, USA: Sage Publications Inc. 220 p. 